\title{
Rates of Recovery to Pre-Fracture Function in Older Persons with Hip Fracture: an Observational Study
}

\author{
Victoria L. Tang, MD, MAS ${ }^{1,2,3}$, Rebecca Sudore, $M D^{1,2}$, Irena Stijacic Cenzer, $M A^{1,2}$, \\ W. John Boscardin, $\mathrm{PhD}^{1,2}$, Alex Smith, MD, MS, MPH ${ }^{1,2}$, Christine Ritchie, MD, MSPH ${ }^{1,2}$, \\ Margaret Wallhagen, RN, PhD, FAAN ${ }^{4}$, Emily Finlayson, $M D, M S^{1,2}$, Laura Petrillo, $M D^{1,2}$, and \\ Kenneth Covinsky, MD, MPH ${ }^{1,2}$
}

'Division of Geriatrics, Department of Medicine, University of California, San Francisco, San Francisco, CA, USA; ${ }^{2}$ Division of Geriatrics, Veterans Affairs Medical Center, San Francisco, CA, USA; ${ }^{3}$ Division of Hospital Medicine, Department of Medicine, Veterans Affairs Medical Center, San Francisco, CA, USA; ${ }^{4}$ Department of Physiological Nursing, School of Nursing, University of California, San Francisco, CA, USA.

BACKGROUND: Knowledge about expected recovery after hip fracture is essential to help patients and families set realistic expectations and plan for the future.

OBJECTIVES: To determine rates of functional recovery in older adults who sustained a hip fracture based on one's previous function.

DESIGN: Observational study.

PARTICIPANTS: We identified subjects who sustained a hip fracture while enrolled in the nationally representative Health and Retirement Study (HRS) using linked Medicare claims. HRS interviews subjects every 2 years. Using information from interviews collected during the interview preceding the fracture and the first interview 6 or more months after the fracture, we determined the proportion of subjects who returned to pre-fracture function.

MAIN MEASURES: Functional outcomes of interest were: (1) ADL dependency, (2) mobility, and (3) stairclimbing ability. We examined baseline characteristics associated with a return to: (1) ADL independence, (2) walking one block, and (3) climbing a flight of stairs.

KEY RESULTS: A total of 733 HRS subjects $\geq 65$ years of age sustained a hip fracture (mean age $84 \pm 7$ years, $77 \%$ female). Thirty-one percent returned to pre-fracture ADL function, $34 \%$ to pre-fracture mobility function, and $41 \%$ to pre-fracture climbing function. Among those who were $\mathrm{ADL}$ independent prior to fracture, $36 \%$ returned to independence, $27 \%$ survived but needed ADL assistance, and $37 \%$ died. Return to ADL independence was less likely for those $\geq 85$ years old ( $26 \%$ vs. $44 \%$ ), with dementia ( $8 \%$ vs. $39 \%$ ), and with a Charlson comorbidity score $>2$ (23\% vs. $44 \%)$. Results were similar for those able to walk a block and for those able to climb a flight of stairs prior to fracture.

CONCLUSIONS: Recovery rates are low, even among those with higher levels of pre-fracture functional status, and are worse for patients who are older, cognitively impaired, and who have multiple comorbidities.

KEY WORDS: hip fracture; geriatrics; function; activities of daily living; palliative care.

Received May 2, 2016

Revised July 29, 2016

Accepted August 10, 2016

Published online September 7, 2016
J Gen Intern Med 32(2):153-8

DOI: $10.1007 / \mathrm{s} 11606-016-3848-2$

(C) Society of General Internal Medicine 2016

\section{INTRODUCTION}

Hip fracture is a public health problem worldwide with the annual incidence estimated to reach 2.6 million in the year 2025 and is associated with excessive mortality. ${ }^{1}$ In 2010 , 289,000 hospitalizations in the US were for hip fracture in older adults. The vast majority of older adults who sustain a hip fracture undergo surgical intervention with post-surgical care pathways focused on rehabilitating patients to their premorbid level of function. Rehabilitative efforts to return the older adult to their pre-fracture function have, therefore, been the predominant goal of research agendas and interventions over the past decades. ${ }^{2-4}$

While hip fracture management has been traditionally focused on curative and rehabilitation models of care in which the focus is on restoring patients to independent function, this model may not meet the needs of patients and families if the actual functional outcomes experienced by patients with hip fracture are less positive. Many patients with hip fracture are developing increasing levels of frailty and functional dependence even before the hip fracture, and the likelihood of returning to their previous level of function may be low in these patients. ${ }^{5}$ Indeed, studies of hip fracture patients in the northeast region of the US have shown a 14-54\% rate of recovery. ${ }^{6-8}$ However, few utilized population-based cohorts with access to pre-fracture functional status data. Identifying patients who are unlikely to return to their prior level of functioning may be useful in targeting patients in whom a supportive care approach, with anticipatory guidance, would complement the traditional rehabilitative care plan.

In order to determine the proportion of older adults who return to their prior level of function after sustaining a hip fracture, we compared and pre- and post-fracture function among those who sustained hip fracture while enrolled in the Health and Retirement Study (HRS). The HRS is a 
cohort representative of the older US population. We first compared pre- and post-fracture function for activities of daily living (ADL), walking, and stair climbing and then assessed which baseline patient demographic and clinical factors predicted particularly low or high likelihood for recovery.

\section{METHODS}

\section{Subjects}

The HRS is a longitudinal study that measures changes in the health and economic circumstances of Americans as they age and is nationally representative of persons over the age of 50. It was initiated in 1992, with new subjects periodically recruited to remain representative of the US population. HRS interviews are conducted by phone or face to face (response rate $>80 \%$ ) every 2 years. If an individual is unable to complete an interview because of physical or cognitive impairment, the interview is conducted with a proxy respondent, generally a family member.

We identified hip fracture cases in HRS subjects aged 65 and older by linking the HRS survey data to Medicare claims. We used Fisher's hip fracture algorithm to identify individuals with hip fracture. ${ }^{9}$ An individual was identified as having a hip fracture if one of the following two conditions was met: (1) the individual was admitted to a hospital with an admitting diagnosis ICD-9 code for hip fracture "820.xx" or (2) a surgeon's charge for operative hip fracture repair (CPT code 27230-27248) supported with either (a) a second surgeon's charge within 2 days or (b) a supporting ICD-9 procedure code for hip fracture surgery (ICD-9 785.5, 790.5, 791.5, 792.5, 793.5). ${ }^{9} \mathrm{We}$ excluded admissions that were considered late effects from a prior hip fracture (ICD9 733.81, 733.82, 905.3, V540-V549) as done in previous studies. ${ }^{9-11}$

Out of 25,146 HRS subjects age 65 or older between 1992 and 2010, 19,006 (76 \%) agreed to have their HRS surveys linked to the Medicare claims. We identified 1,124 hip fractures among those subjects. Since we used Medicare claims to identify comorbidities prior to the hip fracture event, we excluded hip fractures that were not preceded by one continuous year of Medicare fee-forservice enrollment. Of the remaining 1,017 hip fractures, $189(19 \%)$ subjects had no HRS interview within 2.5 years before or after the hip fracture event and were excluded. A 2.5 years' timeframe was used because of the uneven timing between the biennial interviews. Subjects that died within 2.5 years after hip fracture were included despite not having an HRS interview after the hip fracture event. Since considerable recovery still occurs during the 6 months after the hip fracture, ${ }^{6}$ we excluded 94 interviews that occurred within this time frame. The resulting cohort included 733 HRS subjects with hip fracture.

\section{Measures}

The primary outcomes were functional recovery after hip fracture in (1) activities of daily living (ADLs), (2) mobility, and (3) stair climbing. ADLs are measured by the number of activities of daily living (i.e., bathing, dressing, eating, toileting, transferring) in which subjects needed assistance. Mobility is measured with three levels of difficulty: no difficulty with walking one block, difficulty walking one block but no difficulty walking across the room, or difficulty walking across the room. Stair climbing is measured as a dichotomous variable: no difficulty with climbing one flight of stairs without resting or difficulty climbing a flight of stairs without resting. Representative sample questions are included in Appendix 1.

For each outcome, we defined functional recovery as survival with a return to pre-hip fracture function, which we term as a subject's "baseline function." To determine the baseline function of each measure, we used the HRS interview obtained preceding the hip fracture, with a maximum window of 2.5 years (mean $=11.6 \pm 7.4$ months). The time frame of 2.5 years is to account for the slightly uneven spacing of interviews across interview waves. To assess post-fracture function, we used the first interview obtained between 6 months and 2.5 years after hip fracture (mean $=12.5 \pm$ 8.1 months). Pre- and post-fracture function used function data provided by proxy respondents when the subjects could not be interviewed $(20.9 \%)$. Returning to baseline function was determined by comparing the pre- and post-fracture survey data and was treated as a dichotomous variable.

The HRS interview data were used to characterize the sample in terms of self-reported age, gender, race or ethnicity (e.g. non-Hispanic white, non-Hispanic black, Hispanic, and other), education, wealth, income, marital status, and nursing home residence. We determined a history of dementia and a Charlson comorbidity score for each subject using Medicare claims. ${ }^{12}$ Dementia was evaluated independent of the Charlson comorbidity score a priori given previous studies suggesting poor outcomes in hip fracture patients with dementia. ${ }^{13,14}$ We also used the Lee Index, a validated prognostic index for 4-year mortality in older adults where a score of 13 is associated with $59 \%$ risk of death within 4 years. ${ }^{15}$ Mortality after hip fracture was determined using National Death Indexlinked data.

\section{Statistical Analysis}

First, we analyzed the outcomes for each baseline function stratum. We calculated the proportion of subjects who: (1) returned to their pre-fracture function, (2) survived but did not recover to their pre-fracture function, or (3) died, as described above.

Next, we calculated the probability of survival with return to a high level of function. We examined the probability of subjects who were ADL-independent returning to ADL independence, the probability of subjects who had no difficulty 
walking a block returning to having no difficulty walking a block, and the probability of subjects who had no difficulty climbing a flight of stairs returning to having no difficulty climbing a flight of stairs. We used logistic regression models to estimate these probabilities across a variety of subgroups defined by clinical and demographic characteristics after adjusting for age and gender. For example, to compare the probability of recovery in subjects with and without dementia, we first fitted a logistic regression model in which the outcome was ADL independence and the predictor variables were dementia (yes/no), age, and gender. Then, using the same distribution of age and gender as in the overall sample, we used this model to calculate the probability of recovery when dementia was set to 1 (present) and when dementia was set to 0 (absent).

All analyses were weighted to account for the differential probability of subject selection and the complex design of the HRS. Statistical analyses were performed using Stata software, version 12 (StataCorp, College Station, TX) and SAS software, version 9.3 (SAS Institute, Cary, NC). The institutional review board at the University of California, San Francisco, approved this study.

\section{RESULTS}

Table 1 presents descriptive information of the 733 subjects with hip fracture. At the time of their hip fracture, the average age of the subjects was $84 \pm 7.3$ years. Most were female (77\%), almost half had a high comorbidity burden (Charlson $>2,44 \%), 38 \%$ had a Lee Index $\geq 13$, and $17 \%$ had a dementia diagnosis. Prior to the hip fracture event, $74 \%$ were independent in their ADLs, $58 \%$ had no difficulty walking one block, and $49 \%$ had no difficulty climbing one flight of stairs without resting.

Rates of returning to baseline ADL, mobility, and climbing function following hip fracture are shown in Fig. 1. Of all subjects, $31 \%$ returned to their prior ADL function, $34 \%$ returned to their prior mobility function, and $41 \%$ returned to their prior climbing ability. Even for subjects with the highest level of function at baseline, recovery rates were low at least 6 months after their hip fracture: $36 \%$ were ADL independent, $32 \%$ had no difficulty walking one block, and $29 \%$ had no difficulty climbing one flight of stairs without resting. About one-third of the subjects with the highest level of function at baseline survived but sustained a functional decline after their hip fracture: $27 \%$ with new ADL dependency, $33 \%$ with new mobility difficulty, and $34 \%$ with new difficulty stair climbing without resting.

Table 2 shows the probability of returning to function among persons who were in the highest level of baseline function for each measure, adjusting for age and gender. The factors that were consistently associated with low rates of functional recovery across all three measures were advanced
Table 1 Baseline Characteristics of Subjects

\begin{tabular}{|c|c|c|}
\hline \multirow{2}{*}{ Characteristics } & \multicolumn{2}{|l|}{ Cohort } \\
\hline & $N^{*}=733$ & $\%$ \\
\hline Age at hip fracture (mean \pm SD) & $84.0 \pm 7.3$ & \\
\hline \multicolumn{3}{|l|}{ Age at hip fracture } \\
\hline $65-74$ years $(\mathrm{n}=)$ & 96 & 12.8 \\
\hline $75-84$ years $(n=)$ & 273 & 39.0 \\
\hline $85-89$ years $(n=)$ & 213 & 29.5 \\
\hline$\geq 90$ years & 152 & 18.7 \\
\hline \multicolumn{3}{|l|}{ Sex } \\
\hline Male & 177 & 23.2 \\
\hline Female & 556 & 76.8 \\
\hline \multicolumn{3}{|l|}{ Race } \\
\hline White & 642 & 92.6 \\
\hline Black & 50 & 3.7 \\
\hline Hispanic & 37 & 3.3 \\
\hline Other & 4 & 0.4 \\
\hline \multicolumn{3}{|l|}{ Education } \\
\hline Greater than high school education & 407 & 57.9 \\
\hline Less than high school education & 326 & 42.1 \\
\hline Income [median (IQR)] & $\begin{array}{l}17 \mathrm{~K}(9 \mathrm{~K}- \\
31 \mathrm{~K})\end{array}$ & \\
\hline Net worth [median (IQR)] & $\begin{array}{l}81 \mathrm{~K}(8 \mathrm{~K}- \\
268 \mathrm{~K})\end{array}$ & \\
\hline \multicolumn{3}{|l|}{ Marital status } \\
\hline Single or widowed & 488 & 68.5 \\
\hline Married or partnered, \% & 244 & 31.5 \\
\hline \multicolumn{3}{|l|}{ Proxy interview } \\
\hline No & 581 & 79.1 \\
\hline Yes & 153 & 20.9 \\
\hline \multicolumn{3}{|l|}{ Lee Index } \\
\hline$<13, \%$ & 449 & 61.6 \\
\hline$>13, \%$ & 284 & 38.4 \\
\hline \multicolumn{3}{|l|}{ Charlson Comorbidity Scale score } \\
\hline$\leq 2$ & 413 & 55.9 \\
\hline$>2$ & 320 & 44.1 \\
\hline \multicolumn{3}{|l|}{ Nursing home residence, $\%$} \\
\hline No & 658 & 9.5 \\
\hline Yes & 75 & 10.5 \\
\hline \multicolumn{3}{|l|}{ Number of ADL dependencies ${ }^{\dagger, \star}$} \\
\hline 0 ADL dependencies & 539 & 74.0 \\
\hline 1 ADL dependency & 87 & 11.1 \\
\hline 2 or more ADL dependencies & 100 & 14.8 \\
\hline \multicolumn{3}{|l|}{ Mobility } \\
\hline No difficulty walking one block & 393 & 57.8 \\
\hline Difficulty walking one block with no & 148 & 20.8 \\
\hline difficulty walking across the room & & \\
\hline Difficulty with walking across the room & 151 & 21.4 \\
\hline Climbing ${ }^{\ddagger}$ & & \\
\hline $\begin{array}{l}\text { No difficulty climbing one flight of stairs } \\
\text { without stopping }\end{array}$ & 326 & 48.7 \\
\hline $\begin{array}{l}\text { Without stopping } \\
\text { Difficulty climbing one flight of stairs } \\
\text { without stopping }\end{array}$ & 368 & 51.3 \\
\hline
\end{tabular}

Reported values incorporate survey weights to account for the complex survey design. Proxy interview was used if subject was physically or cognitively unable to complete the interview

* some Ns may be unweighted

$\uparrow A D L$ dependency: needing assistance to complete the activity of daily living $(A D L) ; A D L$ consists of bathing, dressing, eating, toileting, transferring

t Number of subjects missing data as follows: Number of $A D L$ dependencies: 7, Mobility: 41, Climbing: 39

$\S$ Lee Index $\geq 13$ is associated with $59 \%$ probability of 4 year mortality

age, dementia, and high comorbidity (Charlson score $>2$ ). Lastly, we found no association among race, marital status, wealth, and income prior to fracture with any of the outcomes. However, less than high school education was associated with a lower probability of returning to ADL independence and with being able to walk one block. In addition, male gender was associated with a lower probability of returning to ADL 


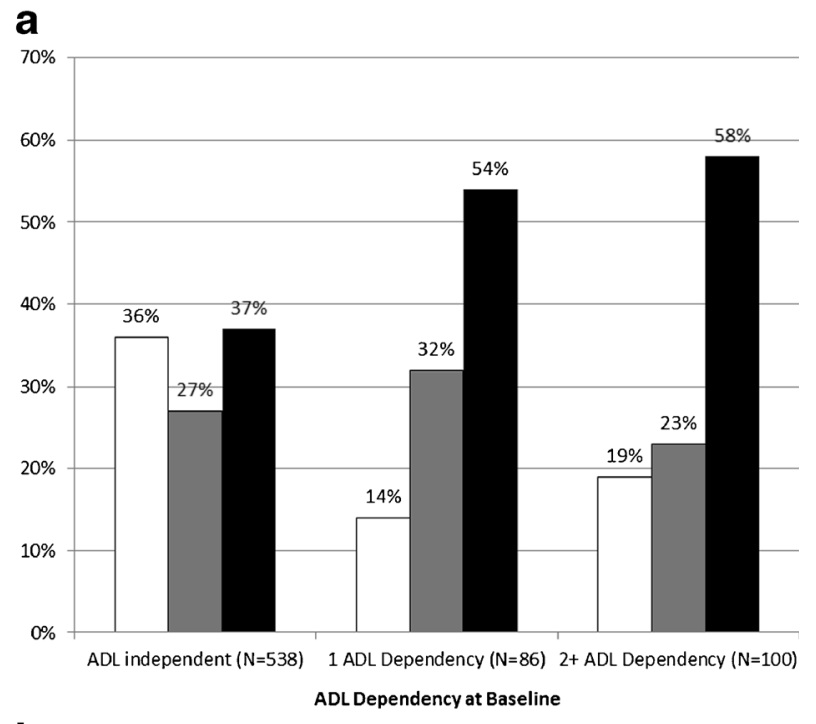

b

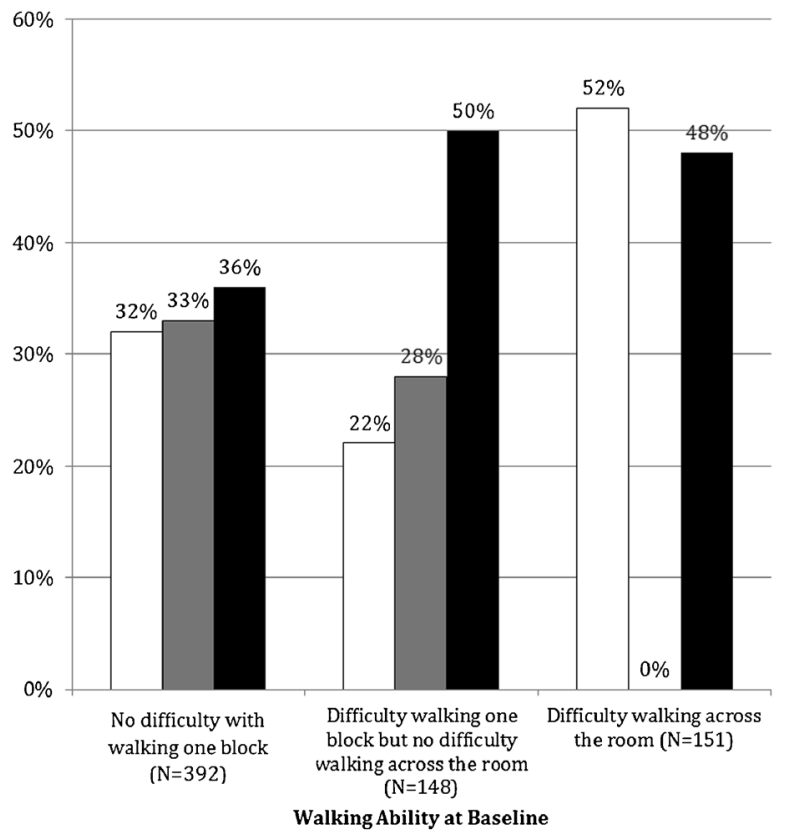

C

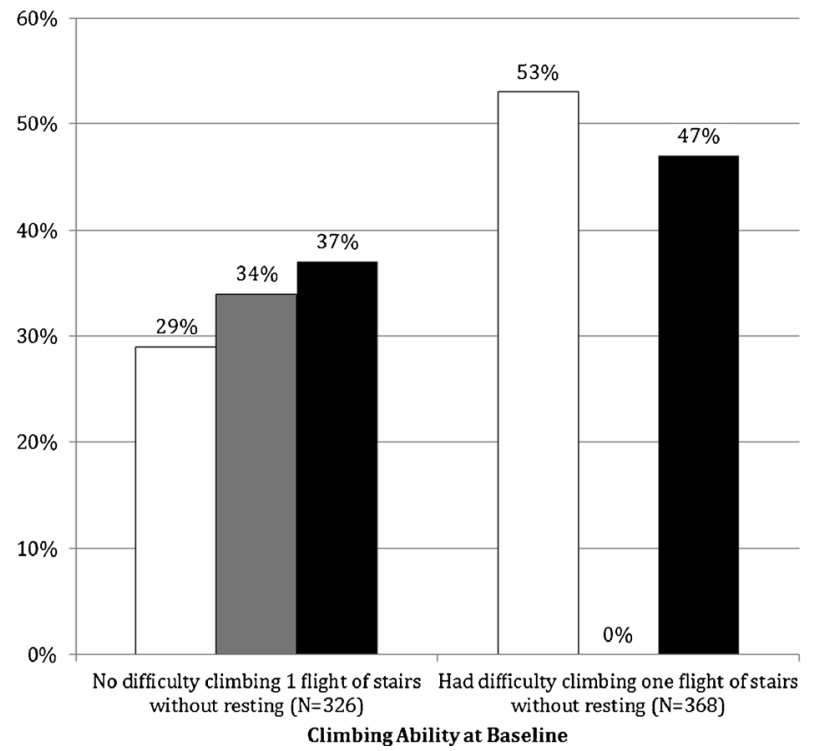

Fig. 1 Likelihood of returning to pre-hip fracture function in groups stratified by baseline function. This figure presents the proportion of HRS subjects with hip fracture returning to their prior ADL, mobility, and climbing function at the follow-up interview 6 months2.5 years after the hip fracture (average, $12.5 \pm 8.1$ months), stratified by their baseline function. a Activities of daily living (ADL). b Walking. c Climbing. Footnote: Baseline function is determined by the pre-hip fracture interview most immediate to the hip fracture event. Returning to pre-hip fracture function was measured by comparing the function reported in the interview 6 months to 2.5 years after the hip fracture to their baseline function (mean $12.5 \pm 8.1$ months).

independence, and nursing home residency was associated with a lower probability of returning to being able to walk at least one block.

\section{DISCUSSION}

Functional recovery in older adults who sustained a hip fracture ranged from 31 to $41 \%$ across our functional outcomes. We found that many older adults who sustained a hip fracture were dependent in ADL, limited in mobility, and limited in stair climbing even before the hip fracture event. Further, the likelihood of recovery to the pre-fracture level of function was less than $50 \%$ regardless of one's previous level of function. Among those with a high baseline function (e.g., ADL independent, no difficulty with walking a block, or no difficulty climbing a flight of stairs without resting), approximately one-third returned to their prior level of functioning. The likelihood of returning to this high level of function was particularly low in those who were older than age 85 , had multiple comorbid conditions, or had dementia.

This study has identified a group of older adults who have a low probability of recovery to their pre-fracture function. With the use of prospectively collected, pre-fracture functional data, this population-based study extends the findings of previous regional studies. In a regional study published in 1990 evaluating functional recovery after a hip fracture, $40 \%$ returned to ADL independence and $54 \%$ returned to walking independently post-hip fracture. ${ }^{6}$ In a recent meta-analysis assessing function 1 year after hip fracture in older adults, $42 \%$ did not return to their pre-fracture mobility, $35 \%$ were unable to walk independently as a result of the fracture, and $14 \%$ of older adults who sustained a hip fracture were no longer able to climb stairs. ${ }^{16}$ Our findings suggest a distinctly lower recovery rate than these previous studies, further emphasizing that a large number of hip fracture patients will suffer long-term functional disability. As compared to prior studies, our study cohort was older, included those with dementia, had a greater prevalence of nursing home patients, and had self-reported pre-fracture functional status data. ${ }^{17}$ Since our subjects were part of a populationbased study, the greater risk of subjects in our study likely more accurately represents the advanced age and severe morbidity of patients who have hip fracture.

Rehabilitative care and a focus on returning to function have been traditional priorities of hip fracture care. However, our 
Table 2 Proportion returning to baseline function among hip fracture subjects with high levels of baseline function. Adjusted for age and gender

\begin{tabular}{|c|c|c|c|c|c|c|}
\hline & $\begin{array}{l}\text { ADL independence } \\
\text { (needs no help in any ADL) } \\
N=539 \%(95 \% \text { CI })\end{array}$ & $\begin{array}{l}p- \\
\text { value }\end{array}$ & $\begin{array}{l}\text { Mobility (no difficulty } \\
\text { walking one block) } N=394 \\
\%(95 \% \text { CI) }\end{array}$ & $\begin{array}{l}p- \\
\text { value }\end{array}$ & $\begin{array}{l}\text { Climbing (no difficulty climbing } \\
\text { one flight of stairs) } N=326 \% \text { ( } 95 \\
\% \text { CI) }\end{array}$ & $\begin{array}{l}p \text { - } \\
\text { value }\end{array}$ \\
\hline $\begin{array}{l}\text { Total } \\
\text { population } \\
\text { Age }\end{array}$ & $35(31-39)$ & & $30(24-35)$ & & $28(22-34)$ & \\
\hline $\begin{array}{l}<85 \\
\geq 85\end{array}$ & $\begin{array}{l}44(37-51) \\
26(20-32)\end{array}$ & 0.002 & $\begin{array}{l}41(34-48) \\
19(12-25)\end{array}$ & $<0.001$ & $\begin{array}{l}34(25-43) \\
21(14-29)\end{array}$ & 0.041 \\
\hline \multicolumn{7}{|l|}{ Gender } \\
\hline $\begin{array}{l}\text { Male } \\
\text { Female }\end{array}$ & $\begin{array}{l}27(19-35) \\
38(33-43)\end{array}$ & 0.038 & $\begin{array}{l}21(11-30) \\
33(26-40)\end{array}$ & 0.07 & $\begin{array}{l}20(10-29) \\
32(24-39)\end{array}$ & 0.077 \\
\hline \multicolumn{7}{|l|}{ Race/ethnicity } \\
\hline $\begin{array}{l}\text { White } \\
\text { Non- } \\
\text { White } \\
\text { Married }\end{array}$ & $\begin{array}{l}35(31-40) \\
30(18-43)\end{array}$ & 0.476 & $\begin{array}{l}30(24-36) \\
24(7-40)\end{array}$ & 0.490 & $\begin{array}{l}29(22-35) \\
18(6-30)\end{array}$ & 0.174 \\
\hline $\begin{array}{l}\text { Married } \\
\text { No } \\
\text { Yes }\end{array}$ & $\begin{array}{l}36(31-40) \\
33(26-41)\end{array}$ & 0.584 & $\begin{array}{l}31(24-38) \\
28(19-37)\end{array}$ & 0.614 & $\begin{array}{l}25(19-31) \\
33(23-42)\end{array}$ & 0.124 \\
\hline \multicolumn{7}{|c|}{ Nursing home } \\
\hline $\begin{array}{l}\text { No } \\
\text { Yes }\end{array}$ & - & & $\begin{array}{l}31(26-37) \\
7(0-18)\end{array}$ & 0.041 & $\begin{array}{l}29(23-35) \\
8(0-24)\end{array}$ & 0.175 \\
\hline $\begin{array}{l}\text { Dementia } \\
\text { No } \\
\text { Yes }\end{array}$ & $\begin{array}{l}39(34-44) \\
8(2-15)\end{array}$ & $<0.001$ & $\begin{array}{l}34(28-41) \\
8(1-14)\end{array}$ & $<0.001$ & $\begin{array}{l}31(25-38) \\
8(0-17)\end{array}$ & 0.023 \\
\hline $\begin{array}{l}\text { Charlson Scal } \\
\quad \leq 2 \\
>2\end{array}$ & $\begin{array}{l}\text { score } \\
44(38-50) \\
23(17-30)\end{array}$ & $<0.001$ & $\begin{array}{l}35(27-43) \\
22(14-30)\end{array}$ & 0.043 & $\begin{array}{l}35(27-42) \\
18(9-27)\end{array}$ & 0.006 \\
\hline \multicolumn{7}{|c|}{ Education less than HS } \\
\hline $\begin{array}{l}\text { No } \\
\text { Yes }\end{array}$ & $\begin{array}{l}39(34-44) \\
29(23-35)\end{array}$ & 0.019 & $\begin{array}{l}33(26-40) \\
23(16-30)\end{array}$ & 0.015 & $\begin{array}{l}29(22-36) \\
26(15-36)\end{array}$ & 0.602 \\
\hline \multicolumn{7}{|c|}{ Income less than median } \\
\hline $\begin{array}{l}\text { No } \\
\text { Yes }\end{array}$ & $\begin{array}{l}36(30-42) \\
34(28-39)\end{array}$ & 0.611 & $\begin{array}{l}30(23-37) \\
29(21-38)\end{array}$ & 0.866 & $\begin{array}{l}30(23-38) \\
24(16-33)\end{array}$ & 0.225 \\
\hline \multicolumn{7}{|c|}{ Wealth less than median } \\
\hline $\begin{array}{l}\text { No } \\
\text { Yes }\end{array}$ & $\begin{array}{l}39(32-45) \\
30(24-37)\end{array}$ & 0.111 & $\begin{array}{l}33(27-39) \\
25(17-34)\end{array}$ & 0.117 & $\begin{array}{l}32(23-40) \\
22(12-31)\end{array}$ & 0.138 \\
\hline
\end{tabular}

*HS: high school

findings of low functional recovery rates, regardless of baseline function, emphasize the need to prepare patients and families with the realistic expectations that recovery may not occur. Furthermore, we determined that age, dementia, and comorbidity burden were associated with a lower likelihood of recovery across the spectrum of pre-fracture function. Our study supports the need for frank discussions with the patient and family about survival prognosis and likelihood of functional recovery. Ascertainment of the patient's values and goals of care, also termed "advance care planning," is critical at this juncture in order to optimize quality of life and assist in future medical decision making. In addition, comprehensive interdisciplinary supportive care particularly focused on psychosocial support and physical supportive home care is appropriate for a large proportion of patients.

Over the past decade, hip fracture co-management models have been developed, shown to improve patient care, and subsequently adopted by some hospitals. ${ }^{18,19}$ In the comanagement model, a geriatrician ensures appropriate medical treatments are undertaken and discusses prognosis; thus, patient and family members develop proper expectations of post-hip fracture recovery and needs. While this model has improved in-hospital post-fracture care, little is known about additional supportive needs by patients and families once the patient returns home. Additional research is needed to better understand the experiences, preferences, and needs of these patients and family members to successfully transition from skilled nursing facilities to home.

Our study design has several strengths. Two main strengths include: (1) the use of a population-based study to identify a representative sample of older adults with hip fracture and (2) the availability of functional status assessments before a hip fracture, thereby not subjected to recall bias. The interpretation of our findings must also take into account several limitations. First, we leveraged an ongoing study to collect data on physical function before and after hip fracture, and, as a result, pre-post functional assessments in both time periods occurred over a 2-year period. Our other work with the HRS hip fracture cohort subjects that persons with hip fracture may start declining in function 9 months before hip fracture. ${ }^{5}$ Therefore, the definition of functional recovery we use in this study may encompass both the functional loss that happened after the fracture and the functional deterioration that led up to the hip fracture. In addition, the validity of using administrative codes for defining a history of dementia has been variable in the literature, though specificity tends to be high for those cases identified. ${ }^{20}$ Also, the functional classification used in this study was patient self-reported and is not based on a validated 
measurement; however, the questions asked reflect what might be asked in a clinical setting (Appendix 1). Lastly, it is possible some of the negative outcomes observed in our paper would have been mitigated by better quality of care, such as the type of care provided by orthogeriatrics units, which are more common in Europe than the US. ${ }^{21}$

In conclusion, we found that older adults who sustain a hip fracture have low rates of returning to pre-fracture function, regardless of their previous physical function. Also, for patients with a high level of pre-fracture function, the likelihood of functional recovery is higher among those without dementia and with a low comorbidity burden. Given the low likelihood of older adults returning to their previous levels of physical function, usual rehabilitation care models should consider integration of supportive care services to meet the needs of older adults and caregivers.

\section{Acknowledgments:}

Contributors: The ten listed authors were the sole contributors to this manuscript. Dr. Tang was responsible for all aspects of the study; Drs. Sudore, Smith, Ritchie, Wallhagen, and Covinsky were involved in study design and critical revision of the manuscript; Drs. Finlayson and Petrillo were involved in the critical revision of the manuscript; Ms. Stijacic Cenzer and Dr. Boscardin were involved in the statistical study design, analysis, and critical revision of the manuscript. All authors had full access to all of the data in the study and take responsibility for the integrity of the data and the accuracy of the data analysis.

Corresponding Author: Victoria L. Tang, MD, MAS; Division of Hospital Medicine, Department of MedicineVeterans Affairs Medical Center, 181G, 4150 Clement Street, San Francisco, CA 94121, USA (e-mail: Victoria.Tang@ucsf.edu).

\section{Compliance with Ethical Standards:}

Funders: Supported by the San Francisco Veterans Affairs Medical Center and Division of Geriatrics, University of California, San Francisco; VLTwas supported in part by the National Institute on Aging (NIA at the National Institutes of Health (NIH) (5-T32-AGOO212) and the Veterans Affairs (VA) Quality Scholars Fellowship Program; RS was supported in part by the VA investigator Initiated Research (11-110-2), NIA at the NIH (RO1 AG045043), Patient-Centered Outcomes Research Institute (CDR-1306-01500), Robert Wood Johnson Foundation, American Cancer Society, John and Wauna Harman Foundation, and S.D. Bechtel, Jr. Foundation; AKS was supported in part by NIA at NIH grants (K23AG040772 and R01AG047897) and the American Federation for Aging Research; $\mathrm{KC}$ and $\mathrm{CR}$ were supported in part by $\mathrm{Na}$ tional Institute of Nursing Research at the NIH (RO1 NRO13347); KC, $C R$, and EF were supported in part by NIA at NIH (P30AG04428); KC was supported by NIA at NIH (K24AG029812); EF was supported in part by NIA at NIH (RO1 AG044425); MW was supported in part by the John A. Hartford Foundation.

Prior Presentations: We presented an earlier version of the manuscript as an oral abstract presentation in consideration for the Mack Lipkin Sr. Associate Member Scientific Presentation Award at the Society of General Internal Medicine National Meeting in Toronto, Canada, in 2015.

Conflict of Interest: All authors declare no conflicts of interest.

\section{REFERENCES}

1. Abrahamsen B, van Staa $\mathbf{T}$, Ariely $\mathbf{R}$, et al. Excess mortality following hip fracture: a systematic epidemiological review. Osteoporos Int. 2009;20(10): 1633-1650.
2. Salpakoski A, Tormakangas T, Edgren J, et al. Effects of a multicomponent home-based physical rehabilitation program on mobility recovery after hip fracture: a randomized controlled trial. J Am Med Dir Assoc. 2014;15(5):361-368.

3. Salpakoski A, Tormakangas T, Edgren J, et al. Walking recovery after a hip fracture: a prospective follow-up study among community-dwelling over 60-year old men and women. Biomed Res Int. 2014;2014:289549.

4. Penrod JD, Boockvar KS, Litke A, et al. Physical therapy and mobility 2 and 6 months after hip fracture. J Am Geriatr Soc. 2004;52(7):1114-1120.

5. Smith AK, Cenzer IS, John Boscardin W, et al. Increase in disability prevalence before hip fracture. J Am Geriatr Soc. 2015;63(10):2029-2035.

6. Magaziner J, Simonsick EM, Kashner TM, et al. Predictors of functional recovery one year following hospital discharge for hip fracture: a prospective study. J Gerontol. 1990;45(3):M101-M107.

7. Eastwood EA, Magaziner J, Wang J, et al. Patients with hip fracture: subgroups and their outcomes. J Am Geriatr Soc. 2002;50(7): 1240-1249.

8. Marottoli RA, Berkman LF, Cooney LM Jr. Decline in physical function following hip fracture. J Am Geriatr Soc. 1992;40(9):861-866.

9. Fisher ES, Baron JA, Malenka DJ, et al. Hip fracture incidence and mortality in New England. Epidemiology. 1991;2(2):116-122.

10. Lauderdale DS, Jacobsen SJ, Furner SE, et al. Hip fracture incidence among elderly Asian-American populations. Am J Epidemiol. 1997; 146(6):502-509.

11. Jacobsen SJ, Goldberg J, Miles TP, et al. Seasonal variation in the incidence of hip fracture among white persons aged 65 years and older in the United States, 1984-1987. Am J Epidemiol. 1991;133(10):996-1004.

12. Charlson ME, Pompei P, Ales KL, et al. A new method of classifying prognostic comorbidity in longitudinal studies: development and validation. J Chronic Dis. 1987;40(5):373-383.

13. Samuelsson B, Hedstrom MI, Ponzer S, et al. Gender differences and cognitive aspects on functional outcome after hip fracture-a 2 years' follow-up of 2,134 patients. Age Ageing. 2009;38(6):686-692.

14. Givens JL, Sanft TB, Marcantonio ER. Functional recovery after hip fracture: the combined effects of depressive symptoms, cognitive impairment, and delirium. J Am Geriatr Soc. 2008;56(6):1075-1079.

15. Lee SJ, Lindquist $\mathbf{K}$, Segal MR, et al. Development and validation of a prognostic index for 4-year mortality in older adults. JAMA. 2006;295(7):801-808.

16. Bertram M, Norman R, Kemp L, et al. Review of the long-term disability associated with hip fractures. Inj Prev. 2011;17(6):365-370.

17. Neuman MD, Silber JH, Magaziner JS, et al. Survival and functional outcomes after hip fracture among nursing home residents. JAMA Int Med. 2014;174(8): 1273-1280.

18. Biber R, Singler K, Curschmann-Horter M, et al. Implementation of a comanaged geriatric fracture center reduces hospital stay and time-tooperation in elderly femoral neck fracture patients. Arch Orthop Trauma Surg. 2013; 133(11):1527-1531.

19. Friedman SM, Mendelson DA, Kates SL, et al. Geriatric co-management of proximal femur fractures: total quality management and protocol-driven care result in better outcomes for a frail patient population. J Am Geriatr Soc. 2008;56(7): 1349-1356.

20. St Germaine-Smith C, Metcalfe A, Pringsheim T, et al. Recommendations for optimal ICD codes to study neurologic conditions: a systematic review. Neurology. 2012;79(10):1049-1055.

21. Prestmo A, Hagen G, Sletvold O, et al. Comprehensive geriatric care for patients with hip fractures: a prospective, randomised, controlled trial. Lancet. 2015;385(9978):1623-1633.

\section{APPENDIX 1: HEALTH AND RETIREMENT STUDY SAMPLE QUESTIONS}

ADL: "Does anyone ever help you [...]?" "dress," "bathe," "eat," "get in or out of bed," and "use the toilet."

Walking: "Because of a health problem do you have any difficulty with walking one block?"

Climbing: "Because of a health problem do you have any difficulty with climbing one flight of stairs without resting?" 